\title{
Effects of alkaline fertilizer and rice cultivation (Oryza sativa L.) on remediation of soils polluted with cadmium (Cd)
}

\author{
Massembo Israël Prince 1; Mankessi François ${ }^{2 *}$; Shaolong Sun 1; Xiao Lin Fan ${ }^{1^{*}}$ \\ ${ }^{1}$ College of Natural Resources and Environment, South China Agricultural University, Guangdong Environmental \\ Engineering Fertilizer Research Center, Wushan Road, Tianhe District, Guangzhou city, Guangzhou 510642 (China). \\ ${ }^{2}$ Ecole Nationale Supérieure d'Agronomie et de Foresterie (ENSAF), Université Marien Ngouabi, BP 13502 \\ Brazzaville, Congo. \\ * Corresponding auteurs: E-mail: framankessi@yahoo.fr; Tél: +242069777411; xlfan@scau.edu.cn , Tél : +86 \\ 18925065558
}

Original submitted in on $23^{\text {rd }}$ October 2020. Published online at www.m.elewa.org/journals/ on $31^{\text {st }}$ January 2021 https://doi.org/10.35759/JABs.157.4

\begin{abstract}
Objective: The objective of this study was to develop a simple and feasible methodology which makes possible restoration of soils polluted by cadmium using two types of fertilizers (alkaline and conventional), and the technique of phytoremediation (low rice variety, and hyper accumulator of cadmium).

Methodology and results: Its application mode was experimented at Guangdong Provincial Research Center for Environmentally Friendly Fertilizer Engineering Technology in Guangzhou, republic of china. The experiment was carried out in a greenhouse, with an average daytime temperature of $25.5^{\circ} \mathrm{C}$, in the city of Guangzhou (China). Polyethylene pots with an inner diameter of $25 \mathrm{~cm}$ and a height of $25 \mathrm{~cm}$ were each filled with $5 \mathrm{~kg}$ of air-dried soil and passed through a $1 \mathrm{~cm} \times 1 \mathrm{~cm}$ mesh of a sieve. Four factors were studied, soil contamination level (soil contaminated with $\mathrm{Cd}$, soil with low $\mathrm{Cd}$ contamination), $\mathrm{pH}$ of the fertilizer (high, $\mathrm{pH}=9.5$, normal pH 5.8), dosage of the fertilizer applied (low level, medium level, high level) and low $\mathrm{Cd}$ accumulating rice variety (Xiangwanxian 12) and hyper $\mathrm{Cd}$ accumulating rice (Yuzhenxiang). Soil samples taken from a depth of 0 to $30 \mathrm{~cm}$ were delivered to the laboratory for analyses. Results obtained showed that the soil pH was higher with the treatment of alkaline fertilizer compared to that of normal fertilizer. The $\mathrm{pH}$ in the soil contaminated with $\mathrm{Cd}$ was 5.80 (alkaline fertilizer applied), higher than that of 5.74 (normal fertilizer applied), alkaline fertilizer improve $\mathrm{pH}$ soil, cure $\mathrm{Cd}$ pollution, bring to rice specific nutrients, at specific moment that rice need to growth and achieve the effect of inhibiting soil pollution, more in hyper accumulation rice than that low accumulation one.

Conclusion and application of results: The results should be helpful in determining appropriate amounts of alkaline fertilizer rice farmers should use to return farm land to productive food crop use, beyond that it was thought cane would be helpful in cadmium uptake from soil. Some rice farmers were reluctant to follow this transition and insisted on growing their rice for survival, alkaline fertilizers can better stop soil pollution and increase the soil pH value. The application of alkaline fertilizer achieves the effect of "controlling Cd pollution with fertilizer".
\end{abstract}

Key words: alkaline fertilizer, $\mathrm{pH}, \mathrm{Cd}$, normal pH fertilizer, accumulation 


\section{INTRODUCTION}

Cadmium (Cd) is a toxic metal recognized throughout the world, due to its high bio-toxicity for both humans and plants (Aoun, 2009). It is a primary soil pollutant that accumulates in the soil as a result of anthropogenic actions such as Zinc (Zn) extraction, metal smelting and industrial wastewater irrigation (Phaenark et al., 2009; Bauddh et al., 2016), which represents a real human health problem. For example, Itai-itai disease appeared after the population ingested contaminated rice with Cd in 1970 in Japan (Franz et al., 2008; Kobayashi et al., 2008). Studies have shown that 70 to $80 \%$ represents the rate of human contamination by $\mathrm{Cd}$ through the absorption of vegetables grown on the ground (Olsson et al., 2002; Wang et al., 2016; Yang et al., 2017). Ingestion of large amounts of $\mathrm{Cd}$ causes severe damage to vital organs, like the lungs and liver, and is the source of cancer and other fatal health problems (Adriano, 2001; Moynihan et al., 2017). Consequently, reducing the concentration of $\mathrm{Cd}$ in the soil is imperative to preserve human health (Miquel, 2001). Phytoremediation is an inexpensive and environmentally friendly technique that reduces the toxicity of heavy metals accumulated in the soil such as Cd (Elizabeth2005; Ji et al., 2011). Larger, hyper$\mathrm{Cd}$ accumulating vegetables such as Thalia caerulescens L. (Alligator-fag), Brassica napus L. (rape), and Solanum nigrum L. (black nightshade) (Zhao et al., 2003; Grispen et al., 2006; Ji et al., 2011) are considered to be potential

\section{MATERIALS AND METHODS}

Materials: A new type of alkaline NPK fertilizer (28-8-15) of $\mathrm{pH}=8.5$, recognized for its ability to improve soil acidity, by its slow release (Fan Xiaolin, 2014) was tested. Also evaluated were two varieties of rice namely, $\mathrm{Cd}$ lower accumulation rice (Xiangwanxian 12), but also $\mathrm{Cd}$ hyperaccumulation rice (Yuzhenxiang) from the Department of Rice, Ministry of Agriculture of republic of china, the criteria for grain selection was similar size and weight as well as germination percentage that must be greater than 90 .

Methods: The experiment was carried out in a greenhouse, with an average daytime temperature of $25.5^{\circ} \mathrm{C}$, in the city of Guangzhou (China). Polyethylene pots with an inner diameter of $25 \mathrm{~cm}$ and a height of 25 phytoremediators of Cd-contaminated soils. Most Cd-accumulating plants are not commercial on a large-scale (Li et al., 2012; Nie et al., 2016). On the other hand, Oryza sativa L., is a species known to have a great ability to accumulate $\mathrm{Cd}$ because of its ability to grow in marshy environments (Niu et al., , 2013; Zhang et al., , 2013; Chen et al., , 2015; Lu et al., , 2015; Zhang et al., , 2015 a; b). Cd is a toxic element that have a relatively high risk of transfer from paddy soil to rice grain. Reducing his accumulation in rice grain is important for food safety and human health (Zhao, et al., 2020). This study was conducted to assess the effects of alkaline fertilizer and rice cultivation on $\mathrm{Cd}$ reduction in soils. Specifically, this involves evaluating the impact of low-Cd accumulation rice (Hunan late indica 12, Hunan rice) and hyper-accumulation rice (Yujianxiang, Hunan Academy of Agricultural Sciences) on soil pollution. Three research questions was formulated:

- does the application of alkaline fertilizer increase soil pH compared to conventional fertilizer?

- does the application of alkaline fertilizer contribute to the reduction of Cadmium in the soil?

- does the cultivation of rice (Oryza sativa L.) have the capacity to accumulate Cadmium stored in the soil?

$\mathrm{cm}$ were each filled with $5 \mathrm{~kg}$ of air-dried soil and passed through a $1 \mathrm{~cm} \times 1 \mathrm{~cm}$ mesh of a sieve. Four factors were studied. The level of soil contamination (soil contaminated with $\mathrm{Cd}$, soil with low $\mathrm{Cd}$ contamination), the $\mathrm{pH}$ of the fertilizer (high, $\mathrm{pH}=9.5$, normal $\mathrm{pH} 5.8$ ), the dosage of the fertilizer applied (low level, medium level, high level) and low $\mathrm{Cd}$ accumulating rice variety (Xiangwanxian 12) and hyper $\mathrm{Cd}$ accumulating rice (Yuzhenxiang). Soil samples taken from a depth of 0 to $30 \mathrm{~cm}$ were delivered to the laboratory for analysis. The soil was air dried, then thoroughly mixed and sieved through $1 \mathrm{~cm} \times 1 \mathrm{~cm}$ mesh. These samples were analysed to estimate the following soil parameters: $\mathrm{pH}$, nitrogen content $(\mathrm{N})$, phosphorus $(\mathrm{P})$, potassium $(\mathrm{K})$ and 
cadmium (Cd). The properties of two soils tested are presented in Table 1.

Table 1: Soil properties

\begin{tabular}{c|c|c|c|c|c}
\hline Soil types & $\mathrm{pH}$ & $\begin{array}{c}\text { Nitrogen } \\
(\mathbf{m g} / \mathrm{kg})\end{array}$ & $\begin{array}{c}\text { Phosphorus } \\
(\mathrm{mg} / \mathrm{kg})\end{array}$ & $\begin{array}{c}\text { Potassium } \\
(\mathrm{mg} / \mathrm{kg})\end{array}$ & $\begin{array}{c}\text { Cd } \\
(\mathrm{mg} / \mathrm{kg})\end{array}$ \\
\hline Soil with Cd & 4.89 & 20.7 & 6.3 & 52.61 & 3.09 \\
Soil without Cd & 5.07 & 4.88 & 3.4 & 22.61 & 0.93 \\
\hline
\end{tabular}

Cd dosage: Harvesting took place 125 days after transplanting. Each plant was subdivided into roots, stems and leaves. The different samples were washed with tap water to remove any debris and then rinsed three times with ultra-pure water. For the determination of the dry mass, these plant samples were subsequently dried in an oven at $75^{\circ} \mathrm{C}$ and then ground to obtain particles with an individual size of less than $0.5 \mathrm{~mm}$. After drying and grinding, the different compartments were weighed separately inside a $0.5 \mathrm{~g}$ flask and digested with $\mathrm{HNO}_{3}$ and $\mathrm{HClO}_{4}$ concentrated in the proportions of $5: 1$ (v/v). The digested samples were diluted with $50 \mathrm{ml}$ of ultrapure water. The $\mathrm{Cd}$ concentration of the samples was measured by inductive plasma mass spectrometry (ICP-MS, Elan DRCe, Perkin Elmer and USA).

Sampling and determination indicators: The soil samples were taken as follows: the first soil sample was taken before transplanting and 24 hours after fertilization, the second at 10 days after fertilization, the third at 30 days after fertilization, the fourth, at 60 days after fertilization, the fifth, at 80 days after transplanting and the sixth at harvest.

Methods of collecting plant samples: Before transplanting three samples of replicas of rice plants were collected, the first sample was collected at the transplanting stage, the 2nd sample, 24 hours after the first application of the fertilizer, the 3rd sample, 24 hours after the second top dressing, the 4th sample took place 24 hours after the third top dressing, the 5th sample of plants at 80 days after transplanting, the 6th plant sample was collected at the time of harvest. At the last sample, in addition to the seedling biomass of rice plants

\section{RESULTS}

Effects of alkaline and conventional fertilizers on the $\mathrm{pH}$ of soils contaminated with cadmium: The results of the analysis of variance indicate significant differences between the fertilizer treatments (conventional and alkaline), concerning the $\mathrm{pH}$ values obtained over time at the alpha level $=0.05($ DMRT, $P<0.05, n=5)$. The and the biomass of the roots, the sample of each organ including grain (seed), leaves, stems and roots was collected, from the 2nd to the 5th plant sample. Two plants from each hole were collected and 8 seedlings from each pot.

Analytical methods: The methods used were to test the soil $\mathrm{pH}$ of each sample, the cadmium of the soil and the cadmium content of the different organs of the rice, the soil of each pot was sampled and homogenized to be air dried, the $\mathrm{pH}$ of the soil was measured using a sol / ultrapure water ratio of $1: 5(\mathrm{w} / \mathrm{v})$ by a $\mathrm{pH}$ meter. To assess the soil $\mathrm{Cd}$ concentration, the soils were digested with concentrated $\mathrm{HCl}$. The extraction of $\mathrm{Cd}$ from soil was based on analysis of the concentrations of $\mathrm{Cd}$ available in soils (GB / T 23739-2009). A total of $25 \mathrm{ml}$ of DTPA extract (0.005 mol.L-1DTPA, 0.1 mol.L-1TEA and $0.01 \mathrm{~mol} . \mathrm{L}-1 \mathrm{CaCl} 2$ ) was added to $5 \mathrm{~g}$ of air-dried sol in a $50 \mathrm{ml}$ polypropylene centrifuge tube. The tubes were shaken end to end for $2 \mathrm{~h}$ at $25^{\circ} \mathrm{C}$, then centrifuged at $5000 \mathrm{rpm}$ for $10 \mathrm{~min}$, the concentrations of $\mathrm{Cd}$ and extractable cadmium were determined using inductive plasma mass spectrometry (ICP- MS, Elan DRCe, Perkin Elmer and USA).

Statistical analyses: Analysis of variance (ANOVA) for the various parameters was performed at the $95 \%$ level. A comparison of means following Duncan's multiple plaque test was subsequently performed. The data in operational solutions were analysed using the SPSS statistical software package. The various means obtained are presented in the form of histograms with standard deviation bars.

results obtained show that the contribution of alkaline fertilizers increased by 0.97 (SE: 0.34), and that the contribution of conventional fertilizers increased by 0.91 (SE: 0.32) mean of $\mathrm{pH}$ value of soils contaminated with cadmium during the growth period (Figures 1 and 2). 


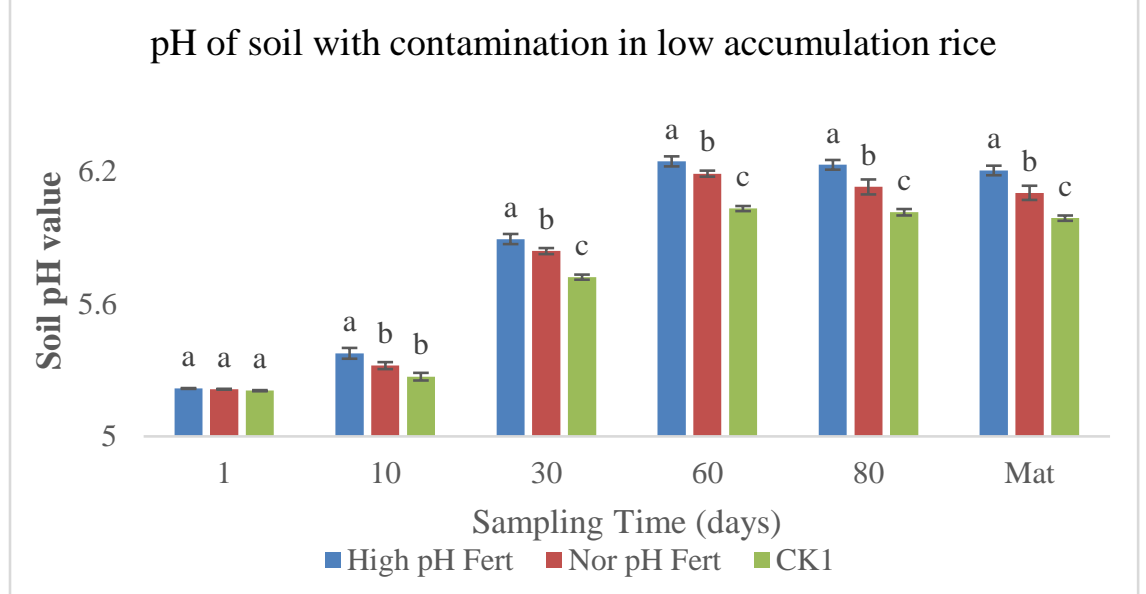

Figure 1: Effect of alkaline and conventional fertilizers on $\mathrm{pH}$ in soils with high $\mathrm{Cd}$ contamination. Bars represent standard deviation intervals and different letters distinguish means which are significantly different.

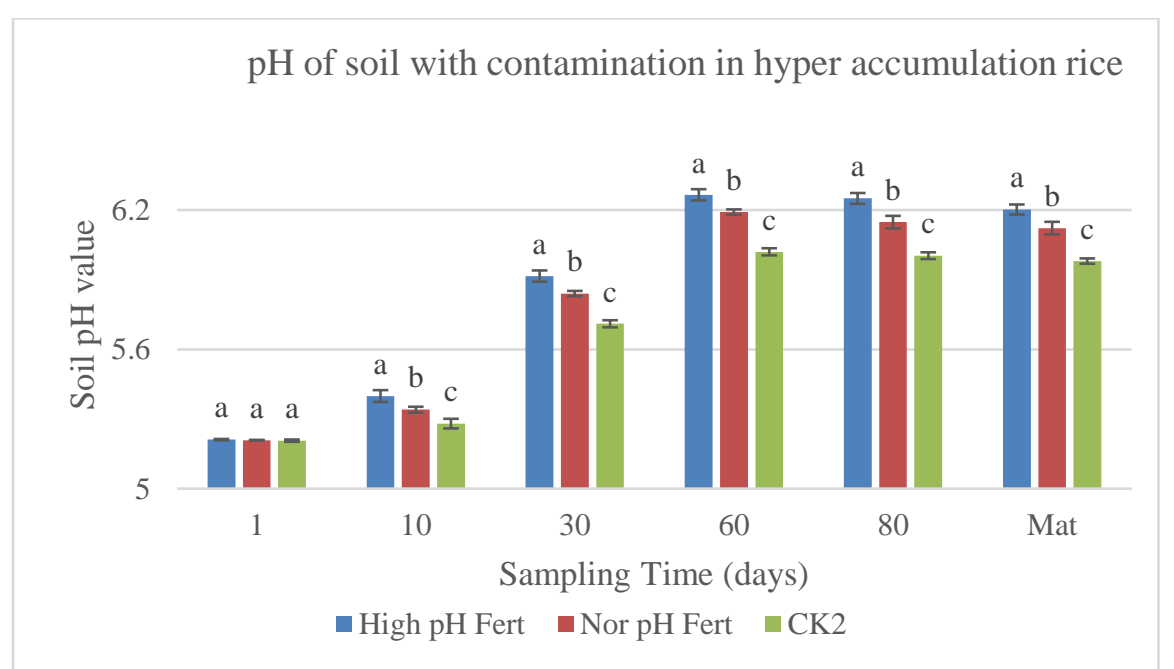

Figure 2: Effect of alkaline and conventional fertilizers on $\mathrm{pH}$ in soils with high $\mathrm{Cd}$ Contamination. Bars represent standard deviation intervals and different letters distinguish means which are significantly different

The results also revealed that for both varieties of rice, the soil $\mathrm{pH}$ was higher $(\mathrm{P}<0.05)$ for treatment with alkaline fertilizer than with conventional fertilizer. Regarding the treatment based on alkaline fertilizer applied, the average $\mathrm{pH}$ obtained is 5.85 (SE: 0.01) during the growth period, higher $(P<0.05)$ than the treatment based on a conventional fertilizer applied 5.79 (SE: 0.01) for varieties of rice with a high accumulation of cadmium. Likewise, for the variety of rice with low cadmium accumulation, the average soil $\mathrm{pH}$ recorded is 5.87 (SE: 0.02) units concerning the treatment with alkaline fertilizer applied, also higher $(P<0,05)$ than the pH 5.80 (SE: 0.02) of the conventional fertilizer treatment applied.

Effects of alkaline and conventional fertilizers on the $\mathrm{pH}$ of soils slightly contaminated by cadmium:
Treatment with alkaline fertilizers increased by 0.92 (SE: 0.32 ) indicate significant differences $(P<0.05)$ compared to the input of conventional fertilizers increased by 0.81 (SE: 0.28 ) the average $\mathrm{pH}$ value of soils contaminated by cadmium during the growing season (Figures 3 and 4). The results obtained show that for both varieties, the soil $\mathrm{pH}$ was higher for the treatment with an alkaline fertilizer than that carried out with a conventional fertilizer. The $\mathrm{pH}$ was 6.02 units on average for the treatment of an applied alkaline fertilizer $(P<0.05)$, higher than that of a conventional fertilizer applied 5.91 units for varieties of rice with high cadmium accumulation. Similarly, for the low cadmium accumulation rice variety, the soil $\mathrm{pH}$ was 5.97 units on average for the alkaline fertilizer treatment applied $(\mathrm{P}<0.05)$ higher than the $\mathrm{pH}$ of treatment with conventional fertilizer applied, pH 5.86 units. 


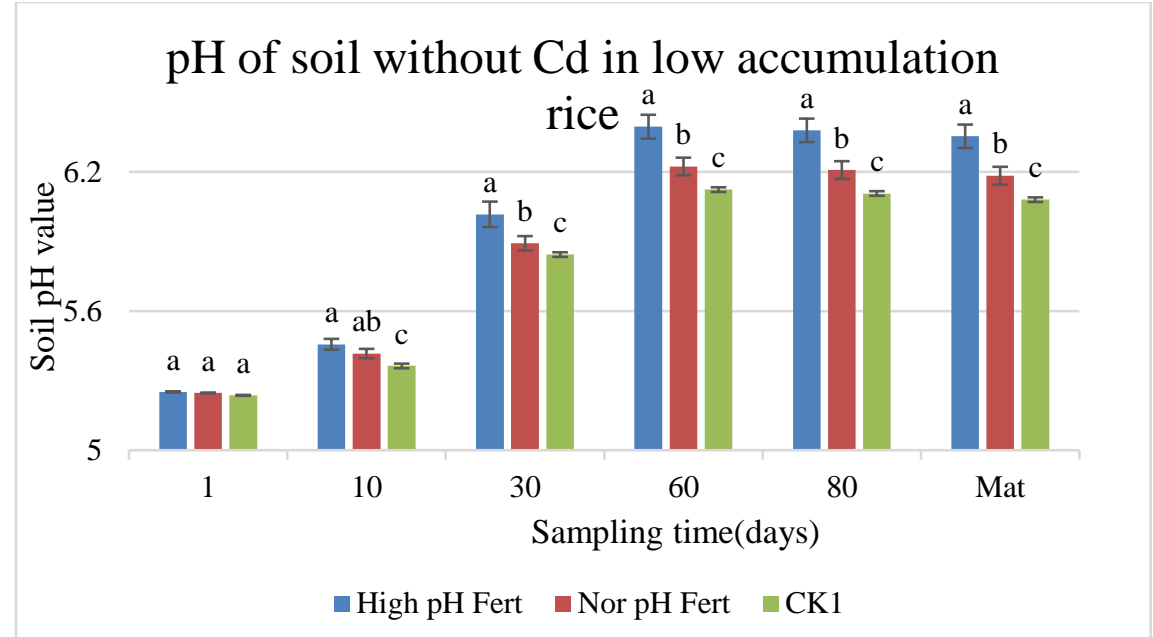

Figure 3: Effects of alkaline and conventional fertilizers on Cadmium accumulation in highly contaminated. Bars represent standard deviation intervals and different letters distinguish means which are significantly different.

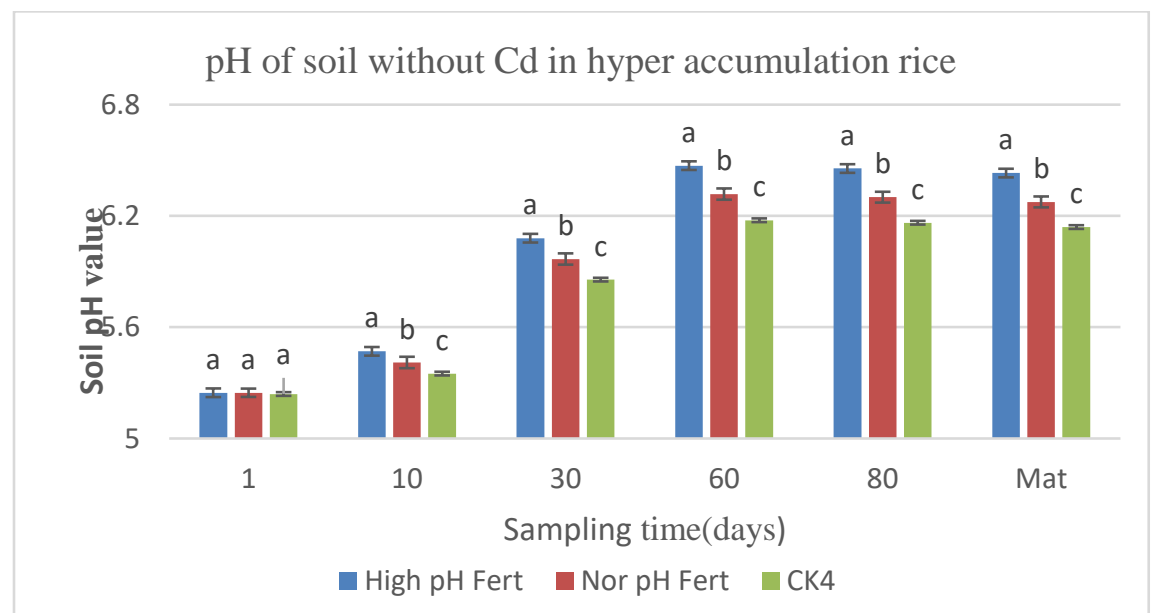

Figure 4: Effects of alkaline and conventional fertilizers on Cadmium accumulation in highly contaminated soils. Bars represent standard deviation intervals and different letters distinguish means which are significantly different. 


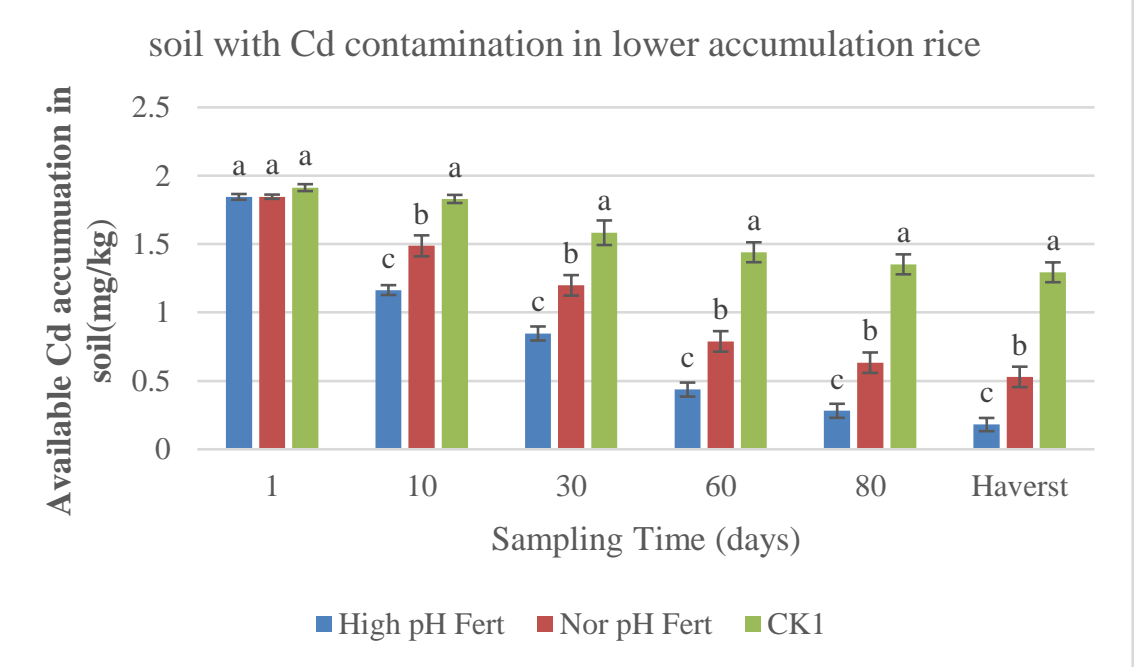

Figure 5: Effect of alkaline and conventional fertilizers on $\mathrm{Cd}$ accumulation in soil with high Contamination. Bars represent standard deviation intervals and different letters distinguish means which are significantly different.

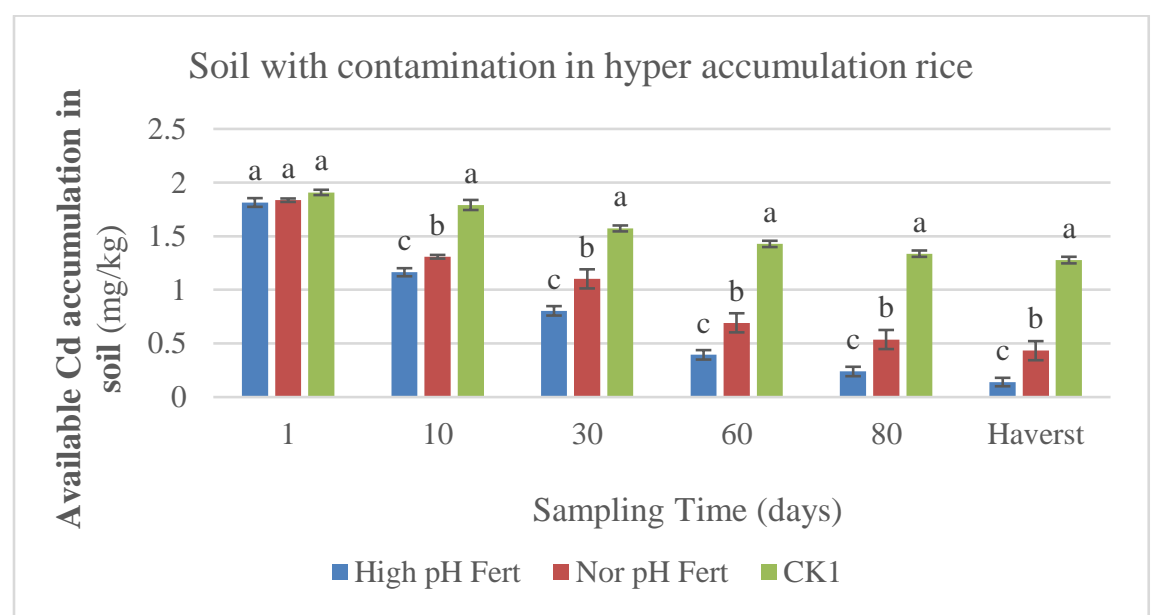

Figure 6: Effect of alkaline and conventional fertilizers on $\mathrm{Cd}$ accumulation in soil with high Contamination. Bars represent standard deviation intervals and different letters distinguish means which are significantly different.

Figures (5 and 6$)$ reports the effects of alkaline and conventional fertilizer on cadmium accumulation of contaminated soils, compared to conventional fertilizer treatment, alkaline fertilizer treatment could significantly reduce cadmium in the soil of the medium growth phase to the final stage of rice. The results showed that for both varieties the contaminated soil cadmium was significantly reduced with treatment of alkaline fertilizers indicating significant differences $(P<0.05)$ compared to treatment of conventional fertilizers. For the treatment with alkaline fertilizer cadmium was $0.75 \mathrm{mg} / \mathrm{kg}$ (SE: 0.04) on average from the period of growth until maturity considerably reduced $(P<0.05)$ than the cadmium of the treatment with Conventional fertilizer which was 0.98 $\mathrm{mg} / \mathrm{Kg}$ (SE: 0.06) for the hyper accumulating rice variety. As well, the cadmium in the soil was $0.79 \mathrm{mg} / \mathrm{kg}$ (SE: 0.04 ) on average from the growth phase to the maturity phase with the alkaline fertilizer treatment applied, also lower $(P<0.05)$ than the conventional fertilizer treatment applied which was $1.08 \mathrm{mg} / \mathrm{kg}$ (SE: 0.06) for the low accumulation rice variety. Application of alkaline fertilizer could significantly reduce the level or quantity of Cadmium available in contaminated soils.

Effects of alkaline and conventional fertilizers on the accumulation of cadmium in lightly contaminated soils: Figures (7 and 8) illustrates the effects of alkaline and conventional fertilizer on the accumulation of cadmium in contaminated soils. Compared with 
conventional fertilizer treatment, alkaline fertilizer treatment would significantly reduce cadmium in the soil from the middle growth stage to the final stage of rice. The results showed that the cadmium in low contamination soil was significantly reduced with the treatment of alkaline fertilizers compared to conventional fertilizers.

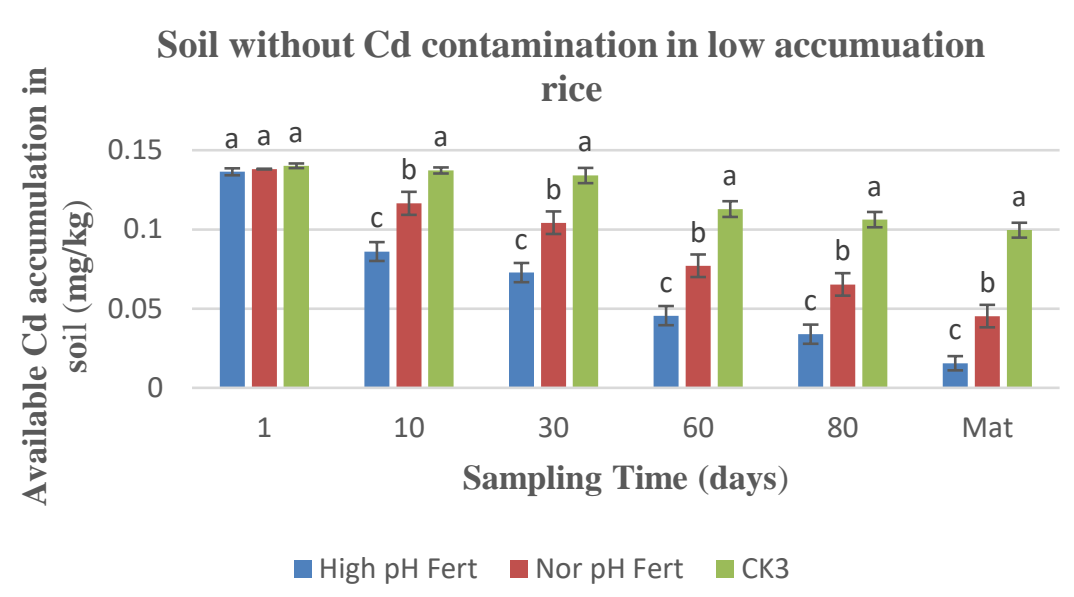

Figure 7: Effect of alkaline and conventional fertilizers on Cd accumulation in soil with less contamination; Bars represent standard deviation intervals and different letters distinguish means which are significantly different.

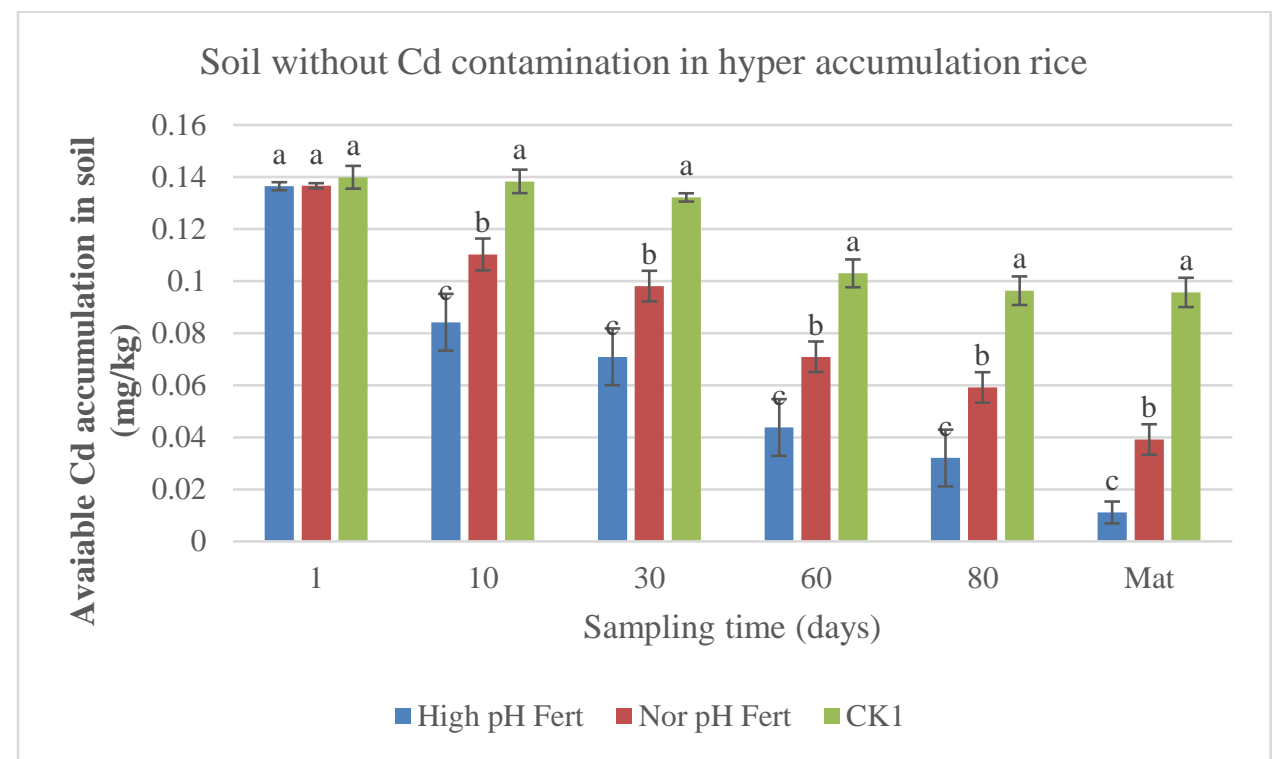

Figure 8: Effect of alkaline and conventional fertilizers on $\mathrm{Cd}$ accumulation in soil with less contamination. Bars represent standard deviation intervals and different letters distinguish means which are significantly different.

Regarding the application of alkaline fertilizers, an average value of $0.06 \mathrm{mg} / \mathrm{kg}$ (SE: 0.005 ) was recorded from the period of growth to maturity considerably reduced than the treatment with the application of conventional fertilizers which recorded a value of 0.08 $\mathrm{mg} / \mathrm{Kg}$ (SE: 0.005 ) for the hyper accumulation rice variety. Regarding the low accumulation rice variety the average cadmium value is $0.06 \mathrm{mg} / \mathrm{kg}$ (SE: 0.008 ) from the growth phase to the maturity phase following the application of alkaline fertilizer lower in cadmium concentration in the soil than the application of conventional fertilizers having a value of $0.09 \mathrm{mg} / \mathrm{Kg}$ (SE: 0.005). Application of alkaline fertilizer could significantly 
reduce the level or quantity of cadmium available in contaminated soils.

Effects of alkaline fertilizers on the accumulation of $\mathrm{Cd}$ in different organs of rice $(\mathrm{mg} / \mathrm{kg})$ : Table 2 shows the effects of fertilizers on $\mathrm{Cd}$ accumulation in different plant regions of rice. Compared to conventional fertilizers, the $\mathrm{Cd}$ content of rice organs decreased with the application of alkaline fertilizer. The results showed for both varieties that the accumulation of cadmium in different rice organs was reduced with the application of alkaline fertilizers. With regard to the highly contaminated soils, the cadmium accumulates in the different organs of rice, was more reduced during the maturation phase with the application of the alkaline fertilizer applied, than the application of the normal fertilizers for the variety of rice. With strong cadmium accumulation, however, similar results were observed in soil with low cadmium contamination.

Table 2: Effects of alkaline fertilizer on the accumulation of $\mathrm{Cd}$ in various organs of rice plant $(\mathrm{mg} / \mathrm{kg})$

\begin{tabular}{|c|c|c|c|c|c|c|}
\hline \multicolumn{2}{|c|}{ Treatments } & \multicolumn{5}{|c|}{ Organs } \\
\hline Soils Types & Rice Types & $\begin{array}{c}\text { Types } \\
\text { Fertilizers }\end{array}$ & Root & Stem & Leaf & Grain \\
\hline $\begin{array}{l}\text { Soils with } \mathrm{Cd} \\
\text { contamination }\end{array}$ & $\begin{array}{l}\text { Low accumulation } \\
\text { rice } \\
\text { Hyper } \\
\text { accumulation rice }\end{array}$ & $\begin{array}{l}\text { High pH Fert } \\
\text { Nor pH Fert } \\
\text { CK1 } \\
\text { High pH Fert } \\
\text { Nor pH Fert } \\
\text { CK2 }\end{array}$ & $\begin{array}{l}0.53 \pm 0.14 c \\
1.49 \pm 0.29 b \\
2.65 \pm 0.56 a \\
0.48 \pm 0.11 c \\
1.48 \pm 0.29 b \\
2.64 \pm 0.58 a\end{array}$ & $\begin{array}{l}0.86 \pm 0.085 c \\
1.13 \pm 0.07 b \\
1.39 \pm 0.03 a \\
0.8 \pm 0.08 c \\
1.10 \pm 0.09 b \\
1.43 \pm 0.04 a\end{array}$ & $\begin{array}{l}0.71 \pm 0.11 c \\
1.72 \pm 0.29 b \\
2.76 \pm 0.18 a \\
0.67 \pm 0.12 c \\
1.70 \pm 0.29 b \\
2.76 \pm 0.07 a\end{array}$ & $\begin{array}{l}5.70 \pm 0.097 \mathrm{c} \\
6.76 \pm 0.31 b \\
7.52 \pm 0.02 \mathrm{a} \\
5.64 \pm 0.097 \mathrm{c} \\
6.70 \pm 0.31 \mathrm{~b} \\
7.50 \pm 0.007 \mathrm{a}\end{array}$ \\
\hline $\begin{array}{l}\text { Soils without } \\
\mathrm{Cd}\end{array}$ & $\begin{array}{l}\text { Low accumulation } \\
\text { rice }\end{array}$ & $\begin{array}{l}\text { Nor pH Fert } \\
\text { CK1 }\end{array}$ & $\begin{array}{l}0.31 \pm 0.05 b \\
0.93 \pm 0.06 a\end{array}$ & $\begin{array}{l}0.36 \pm 0.04 b \\
0.42 \pm 0.01 a\end{array}$ & $\begin{array}{l}0.53 \pm 0.01 C \\
0.27 \pm 0.08 b \\
0.45 \pm 0.007 \\
a\end{array}$ & $\begin{array}{l}0.51 \pm 0.01 \mathrm{C} \\
0.77 \pm 0.06 \mathrm{~b} \\
1.035 \pm 0.07 \mathrm{a}\end{array}$ \\
\hline contamination & $\begin{array}{l}\text { Hyper } \\
\text { accumulation rice }\end{array}$ & $\begin{array}{l}\text { High pH Fert } \\
\text { Nor pH Fert } \\
\text { CK2 }\end{array}$ & $\begin{array}{l}0.04 \pm 0.01 c \\
0.30 \pm 0.05 b \\
0.92 \pm 0.07 a\end{array}$ & $\begin{array}{l}0.22 \pm 0.01 c \\
0.36 \pm 0.02 b \\
0.42 \pm 0.01 a\end{array}$ & $\begin{array}{l}0.04 \pm 0.01 c \\
0.29 \pm 0.09 b \\
0.47 \pm 0.06 a\end{array}$ & $\begin{array}{l}0.50 \pm 0.01 \mathrm{c} \\
0.76 \pm 0.06 \mathrm{~b} \\
1.02 \pm 0.07 \mathrm{a}\end{array}$ \\
\hline
\end{tabular}

Legend:_Nor: Normal, _Nor pH Fert: Normal pH fertilizer, _High pH Fert: High pH fertilizer CK: Witness (without using fertilizer)

The accumulation of cadmium in the various organs of the rice was less with the application of the alkaline fertilizer compared to the application of conventional fertilizers. Application of alkaline fertilizer promotes

\section{DISCUSSION}

This study found that compared to conventional fertilizers, alkaline fertilizers can increase soil $\mathrm{pH}$ and reduce soil $\mathrm{Cd}$. The application of alkaline fertilizer increases the $\mathrm{pH}$ of soils with the neutralization time. This study proved that the continued application of alkaline fertilizers within 6 months of growing potted rice will continue to significantly increase the $\mathrm{pH}$ value of the soil. Therefore, in agricultural production, fertilizers composed of alkaline fertilizers should be used instead of fertilizers composed of conventional fertilizers, not only can it affect the growth of crops, but also can play an alkaline suppressing property acid soil can achieve the goal of restoring soil neutrality through the long-term growth (height), increases length, stalk leaves, grain, roots of rice during the growing period, the $\mathrm{Cd}$ content of each organ of the rice at harvest was in the order root> stem $>$ grain $>$ leaf.

application of alkaline fertilizers, there by resolving the damage caused to the soil by the long-term application of physiological acid fertilizers such as urea. When soil acidity is improved, it is to fundamentally control heavy metal pollution like $\mathrm{Cd}$ caused by soil acidification. It was found that exchangeable $\mathrm{Cd}$ in soil is significantly ( $p$ $<0.05$ ) negatively correlated with soil $\mathrm{pH}$, and the content of exchangeable $\mathrm{Cd}$ in soil decreases with increasing soil pH (Muhammad et al.,, 2012; Liang Qiaofeng, 2010; Wang et al.,, 2015) found that heavy metals in river sediments are mainly released under acidic conditions and their release rate decreases rapidly with increasing soil $\mathrm{pH}$. The $\mathrm{pH}$ reduction of the precipitate can increase 
the rate of release of $\mathrm{Cd}$ from weakly acid-extracted and reducible $\mathrm{Cd}$ (Wang Yaping, 2012). The $\mathrm{pH}$ value of the leach solution is also inversely proportional to the $\mathrm{Cd}$ content of the stone charcoal filtrate (Song Mingyi et al., 2011). The use of lime and other alkaline substances to treat and passivate $\mathrm{Cd}$ pollution is used, for example, the application of lime and alkaline wastes in the paddy field reduced the effective $\mathrm{Cd}$ content of the soil by $33.2 \%$ $38.7 \% 60$ days after transplanting rice, and the $\mathrm{Cd}$ content of brown rice was reduced by $27.1 \% \sim 65.1 \%$ compared to the treatment without applying the modifier (Liu Zhaobing et al., 2011). Soil pH value increased with increasing amount of alkaline serpentine powder, $\mathrm{Cd}$ content exchangeable in soil with alkaline serpentine powder decreased by $17.42 \% \sim 53.72 \%$ compared to the witness (Wang Xue et al., 2015). Application of lime can reduce the effective $\mathrm{Cd}$ activity of soil (Zhou Xiangyu, 2012), and increasing the amount of lime can increase $\mathrm{Cd}$ bound to iron manganese oxide and $\mathrm{Pb}$ bound to carbonate, reducing thus the bioavailability of soil $\mathrm{Cd}$ and $\mathrm{Pb}$ (Liang Qiaofeng, 2010). Jiao-Feng $\mathrm{Gu}$ (2019) showed that after application of $\mathrm{Cd}$ and As fertilizers, the concentrations of the exchangeable fraction and the extraction of TCLP in the soil decreased with the growth of the rice plants. $\mathrm{Cd}$ concentrations in rice tissue decreased during tillering, filling and ripening in situ

\section{CONCLUSION AND APPLICATION OF RESULTS}

This study is part of a perspective of assessing and eliminating the environmental risks inherent in soils polluted by cadmium, the objective is to develop a simple and feasible methodology, which makes it possible to restore soils polluted by cadmium using two types of fertilizers (alkaline, conventional), and the technique of phytoremediation (low rice variety, and hyper accumulator of cadmium). Analysis of the results obtained after cultivation, confirms the decrease of $\mathrm{Cd}$ in soils highly and slightly contaminated by cadmium. This fact demonstrates the effectiveness of alkaline fertilizers, and rice varieties to absorb, fix, and reduce the $\mathrm{Cd}$ in soil. Our results showed also the decrease of $0.79 \mathrm{mg} / \mathrm{Kg}$ (alkaline fertilizer), a decrease of $1.08 \mathrm{mg} / \mathrm{Kg}$ (conventional fertilizer) with regard to highly polluted

\section{ACKNOWLEDGEMENTS}

Grateful thanks are due to everyone who has assisted in the research and preparation of this paper. Specially to professor XIAOLIN Fan for financial support to carry out the experiment and advice to write and supply sanitation stages, while as concentrations in rice tissue decreased only at ripening stage. The results of (Yasir et al., 2018) showed that the treatment of fertilizers showed the best effects on reducing the phyto availability of $\mathrm{Cd}$ and $\mathrm{Pb}$ in the soil and absorption by early rice. (Xuiling yin et al., 2017) state that the natural sepiolite remediation mechanisms for $\mathrm{Cd}$ pollutant in paddy soils could be summarized as the collective effects of soil chemistry and plant physiology. The results of (Huan Jing ke Xue, 2020) show that the application of calciummagnesium-phosphorus fertilizer improves the effect of reducing the $\mathrm{Cd}$ content of brown rice by lime associated with sepiolite. Finally, it can both meet the quality safety requirements of brown rice and increase the yield of brown rice in $\mathrm{Cd}$ contaminated paddy soils. Although the application of alkaline substances such as lime can passivate the activity of $\mathrm{Cd}$ heavy metals to some extent and reduce their biological efficiency, the long-term application of lime and other alkaline wastes will inevitably result in compaction of the soil and lead to other pollution. Increase the soil load. Previous research results from this research group show that the application of alkaline fertilizers can significantly improve soil acidity and reduce the $\mathrm{Cd}$ content of rice while increasing the 1000 grain weight of rice (Zhang Liang et al., 2016).

soils, there is also a decrease of $0.06 \mathrm{mg} / \mathrm{kg}$ (alkaline fertilizer), a decrease of $0.08 \mathrm{mg} / \mathrm{Kg}$ (conventional fertilizer) for soils slightly contaminated by cadmium. These results showed that alkaline fertilizers can be used as long-term compound fertilizers for growing nutrient crops, as soil amendments to treat acidified soils, solve the problem of $\mathrm{Cd}$ soil pollution, unlike to conventional fertilizers, which are prone to defertilization. Ultimately, to fully exploit the nutritional effect of long-acting alkaline fertilizers and the characteristics of soil improvement, it is necessary to understand and master the properties of fertilizers and to apply appropriate fertilization methods to fully exert their effects.

experimental network room of environmental friendly fertilizer engineering technology research center of Guangdong University of South China agricultural University to finish the work. 


\section{REFERENCES}

Adriano, DC, 2001.Trace elements in terrestrial environments: Biogeochemistry, bioavailability and risks of metals. 2nd Edition, Springer, New York, 867. https://doi.org/doi.10.1007/978-0-387-21510-5

Aoun $M, 2009$. Action du cadmium sur les plants de moutarde indienne [Brassica juncea (L.) Czern] néoformés à partir de couches cellulaires minces et issus de semis. Analyses physiologiques et rôle des polyamines. Ecotoxicité et santé environnementale. Thèse de doctorat, Université de Bretagne Occidentale, 139 p. DOI: DOI: https://tel.archives-ouvertes.fr/tel-00385705

Bauddh Kuldeep, Singh Korstad, 2016. Ricinus communis: A robust plant for bio-energy and phytoremediation of toxic metals from contaminated soil. Ecological Engineering Journal. Volume 84, 640-652. DOI: http://dx.doi.org/10-3084-0 16.

Borui Liu, Qing Huang, Xiang Guo, Mingying Gui, 2015. Study of heavy metal concentrations in wild edible mushrooms in Yunnan Province. China Food Chemistry 188: 294-300. DOI: https://doi.org/10.1016/i.foodchem.2015.05.01 $\underline{0}$.

CAI Zi-hua, Song Ming-yi, HU Yan-hua, HUANG Chunlei, WANG Jia, 2011.The discovery of lake Facies selenium-rich soil and its ecological. China vol. 35 (2): 248-253.

Chen, Longshot Zheng, Siwei Zhang, 2015. The updated incidences and mortalities of major cancers in China. Chinese Journal of Cancer 34 (3). DOI: https://doi.org/10.1186/s40880-015-0042-6.

Elizabeth Pilon Smits, 2005. Phytoremediation. Annual Review of Plant Biology. vol. 56:15-39. DOI: https://doi.org/10.1146/annurev.arplant.56.032 604.144214.

Fan Xiaolin and Li Jin, 2014. The effect of alkaline fertilizers on regulating the acidity of banana orchard soil and preventing and controlling banana wilt. Journal of Plant Nutrition and Fertilizer, Volume 40(4): 938-946.

Franz E, Romkens $P$, Van Raamsdonk L, Van Der FelsKlerx I, 2008. A chain modeling approach to estimate the impact of soil cadmium pollution on human dietary exposure. J. Food Prot. 71(12): 2504-2513. DOI: https://doi.org/10.4315/0362-028x-71.12.2504
Grispen J, Nelissen Hans JM, Verkleij Jos AC, 2006. Phytoextraction with Brassica napus L.: a tool for sustainable management of heavy metal contaminated soils. Environ Pollut. 144(1):7783. DOI: https://d oi.org/10.1016/j.envpol.2006.01.007

Hamid YasirTang, Lin, XiaoziWang, Bilal Hussain MuhammadYaseen, Xiaoe Yang, 2018. Immobilization of cadmium and lead in contaminated paddy field using inorganic and organic additives. Scientific Reports 8 (1):17-39. DOI: $\quad$ https://doi.org/10.1038/s41598-01835881-8.

Järup L, Berglund M, Elinder C.G, Nordberg G, Vanter $M, 1998$. Health effects of cadmium exposurea review of the literature and a risk estimate. Scand Journal of Work Environ. Health 24 (1):1-5.

DOI: https://www.jstor.org/stable/40967243

Kobayashi E, Suwazono Dochi, Honda Nishijo M, Kido T, 2008. Estimation of Benchmark doses as threshold levels of urinary cadmium based on excretion of $\beta 2$-microglobulin in cadmium polluted and non-polluted regions in Japan. International Journal of Environmental Health Research.16 (5):108-112. DOI: https://doi.org/10.1080/09603120600869174.

Kobayashi J, 1978. Pollution by cadmium and the Itai-Itai disease in Japan. In: Oeheme Toxicity of Heavy Metals in the Environment. Marcel Dekker New York, pp. 199-260.

Liang L Z, Zhao X Q, Yi X Y. 2013. Excessive application of nitrogen and phosphorus fertilizers induces soil acidification and phosphorus enrichment during vegetable production in Yangtze River Delta, China. Soil Use and Management, 29 (2):161-168. DOI: https://doi.org/10.10.1111/sum.12035

Liang Zhang, Wei Li, Yiyan Wu, Xianbin Wang, Sung-lk Park, Heung Mook Kim, Jae-Young Lee, Pablo Angueira, Jon Montalban, 2016. Layereddivision-multiplexing: Theory and practice Transactions on Broadcasting 62 (1): 216-232. DOI: https://doi.org/10.1109/TBC.2015.2505408

Ling Tang, XiaofengJi, Yunyang, Li, Xiuyi Hua, 2019. Pollution characteristics, sources and health risk assessment of human exposure to $\mathrm{Cu}, \mathrm{Zn}$ $\mathrm{Cd}$ and $\mathrm{Pb}$ pollution in urban street dust across china between 2009 and 2018. Environment 
International, 128: 430-437. DOI: https://doi.org/10.10.16/j.envint 2019.04.046.

Liu X, Zhou J, Li W, 2014. The combined effects of urea application and simulated acid rain on soil acidification and microbial community structure. Environmental Science and Pollution Research, 21(10): $\quad$ 6623-6631. DOI: https://doi.org/10.1007/s11356-014-2573-9

McGrath SP, Zhao F-J, 2003. Phytoextraction of metals and metalloids from contaminated soils. Current Opinion in Biotechnology 14 (3): $277-$ 282.DOI: https://doi.org/10.10.16/S0958-1669 (03)00060-0

Moynihan Peterson KE, Cantoral, Song PX, Jones A, Solano-González, Meeker JD, Basu N, TéllezRojo M, 2017. Dietary predictors of urinary cadmium among pregnant women and children. Science of the Total Environment 575 (5):1255-1262. DOl: https//doi.org/10.1016/j.scitotenv.2016.09.204

Muhammad I, Puschenreiter M, Wenzel W, 2012. Cadmium and $\mathrm{Zn}$ availability as affected by $\mathrm{pH}$ manipulation and its assessment by soil extraction, DGT and indicator plants. Science of the Total Environment, 416: 490-500. DOI: https//doi.org/doi.org/10.1016/j

Muhammad Zia-ur Rehman, Hinnan Khalid, Muhammad Umair, 2019. Inorganic Amendments for the Remediation of Cadmium-Contaminated. Soils Cadmium Tolerance in Plants, 113-141. DOI: https://doi.org/10.10.16/B978-012-8157947.00004-7.

Niu Shuhe, Wei Jiayi, BaiSiqi, Wang Dandan JI, 2013. Identification of rice cultivar with exclusive characteristic to $\mathrm{Cd}$ using a field-polluted soil and its foreground application. Environmental Science and Pollution Research 20 (4): 26452650.

DOI: https://doi.org/10.10.80/15226514.2014.95516 $\underline{8}$.

Olsson, IM , Bensryd I, Lundh, T, Ottosson, H, Skerfving, S, Oskarsson, A, 2002. Cadmium in vassociation of renal effects. Environ. Health Perspect. 110: 1185-1190.

Phaenark $\mathrm{P}$, Pokethitiyook $\mathrm{M}$, Kruatrachue $\mathrm{C}$, Ngernsansaruay, 2009. $\mathrm{Cd}$ and $\mathrm{Zn}$ accumulation in plants from the Padaeng zinc mine area. International Journal of Phytoremediation, 11: 479-495. DOI: https://doi.org/10.1080/15226510802656243.
Puhui Ji, Tieheng Sun, Yufang Song, Leigh Auckland, Yang Liu, 2011.Strategies for enhancing the phytoremediation of cadmium-contaminated agricultural soils by Solanum nigrum L. Journal of Environ pollut.159 (3):762-8. DOl: https://doi.org/10.10.16/i.envpol.2010.11.029

Song $\mathrm{H}$, Che Z, Cao W, 2016. Changing roles of ammonia-oxidizing bacteria and archaea in a continuously acidifying soil caused by overfertilization with nitrogen. Environmental Science and Pollution Research, 23 (12):11964-74. DOl: https://doi.org/10.1007/s11356-016-6396-8

Wang C, Li W, Yang Z, 2015. An invisible soil acidification: Critical role of soil carbonate and its impact on heavy metal bioavailability. Scientific Reports, 5(1).12735. DOI: https//doi.org/10.1038/srep12735

Wang M, Chen W, Peng C, 2016. Risk assessment of $\mathrm{Cd}$ polluted paddy soils in the industrial and township areas in Hunan, Southern China. Chemosphere, 144: 346-351. DOI: https: //doi.org/10.1016/j.chemosphere.2015.09.001.

Xue Wang, Mengyan Nie, Chuan Ting Wang, Shun Cai Wang, Nong Gao.2015. Micro hardness and corrosion properties of hypoeutectic Al-7Si alloy processed by high-pressure torsion. Materials and Design. Volume 83:193-202. DOI: https//doi.org/10.1016/j.matdes.2015.06.018

Yan DM, Guo ZH, Huang FL, Ran HZ, Zhang L, 2020. Effect of Calcium Magnesium Phosphate on Remediation Paddy Soil Contaminated with Cadmium Using Lime and Sepiolite. National Library of Medicine. DOI: https://doi.org/10.13227/j.hjkx.201909095

Yang Y, Chen W, Wang M, Li Y, Peng C, 2017. Evaluating the potential health risk of toxic trace elements in vegetables: accounting for variations in soil factors. Sci. Total Environ. 584: 942-949.

DOI: https//doi.org/10.1016/j.scitotenv.2017.01.143.

Yasir Hamid, Lin Tang, Xiaozi Wang, Bilal Hussain, Muhammad Yaseen, Muhammad Zahir Aziz, Xiaoe Yang,2018. Immobilization of cadmium and lead in contaminated paddy field using inorganic and organic additives. Sci. Rep. 8, 1739. DOI: https://doi.org/10.1038/s41598-01835881-8https://doi.org/10.1038/s41598-01835881-8.

Yingming Huang, Rong Huang, Qingqing Xie, ZhongleiCai, Yanming Liang, Xue Feng, 2019. 
Remediation mechanisms for $\mathrm{Cd}$-contaminated soil using natural sepiolite at the field scale. Environmental science; processes and impacts 19, 1563-1570. DOI: https://doi.org/10.1039/C7EM00262A.

Zhang L, Tong Y.A, Liang T, Zhang FS, 2015. Quantifying atmospheric nitrogen deposition through a nationwide monitoring network across. China Atmospheric Chemistry and Physics, $15 \quad$ (21):12345-12360. DOI: https//doi.org/10.5194/acp-15-12345-2015

Zhao Fang Jie, Peng Wang, 2020. Arsenic and cadmium accumulation in rice and mitigation strategies. Plant Soil 446, 1-21. DOI: https://doi.org/10.1007/s11104-019-04374-6.

Zhao Yunde, Helen Black well I, 2003. Chemical genetic approaches to plant biology. Plant Physiology, 133 (2): 448-455. DOI: https//doi.org/10.1104/pp.103.031138

Zhitong Yao, Jinhui Li, Henghua Xie, Conghai Yu, 2012. Review on remediation technologies of soil contaminated by heavy metals. Procedia Environmental Sciences 16: 722-729. DOI: https://doi.org/10.10.16/i.proenv.2012.10.099.

Zhou S, Liu J, Xu M, 2015. Accumulation, availability, and uptake of heavy metals in a red soil after 22-year fertilization and cropping. Environmental Science and Pollution Research, 22(19):15154-15163.

DOI: https://doi.org/10.1007/s11356-015-4745-7

Zhou W, Kuibo Y, Andrew R. 2015.The observation of square ice graphene questioned. Nature 528 , 443-445.

DOI: http://dx.doi.org/10/1038/nature16145. 